\title{
Optimization Design of Thermal Test Waveguide Link for Communication Satellite
}

\author{
SHAO Yu-jie ${ }^{1, a}$, Yu Zhong-xi ${ }^{2}$, DU Chun-lin ${ }^{1}$ and WANG Jing ${ }^{1}$ \\ ${ }^{1}$ Thermal Test Technology and Product Department, Beijing Institute of spacecraft environment engineering , 104 \\ Youyi Street Haidian, Beijing, PLC. \\ ${ }^{2}$ Shandong Institute of Space Electronic Technology, No.513, Hangtian Road, Yantai, Shandong Province, PLC.
}

\begin{abstract}
Problems in structure of water load power meter and waveguide assemblies of the communication satellite transponder thermal test. This paper analyzes water load layout and reasons of signal attenuation, and then it proposes an optimization that put water load detached from satellite's board. To ensure the reason of waveguide signal loss, this paper discusses the internal electromagnetic field distribution and currents on waveguide wall. the result of signal loss value showed that the new optimization can decrease signal attenuation value and shorten the process of crafts implementation.
\end{abstract}

\section{Introduction}

According to the statistics, as of March 2016, China put hundreds of satellites in orbit so that ranked the third in the world only preceded by America and Russia. At present, most of our orbiting satellites were related to information transmission[1], for example, the optical remote sensing satellite, military reconnaissance satellite, meteorological satellite, space exploration satellite and so on. However, the communication link usually use microwave to achieve signal transmission between satellites to satellites, and satellites to ground stations. In order to verify thermal design of the satellite correctly and the transponder subsystem work properly, it's Important to test transponder system on the ground[2].

After determining the radio frequency connection and power absorption scheme in the chamber, experimental designer set the cable and waveguide connection mode according to the sub-system of each frequency transponder. The frequency band absorption scheme mostly adopted water-loads absorption mode for thermal test or connected a high-power attenuation device outside the chamber. At present, the domestic general RF power absorption scheme needs to take into account the water-load. Therefore, the design of waveguide path and subsequent installation has very high requirements. Especially in the thermal test for large-scale communications and experimental satellite, such as high-throughput systems, have a certain impact on the longevity of satellites.

This article compared the measured values of electrical performance in different layouts, and thus improves the design of waveguides and water-loads. It aims to illustrate the implementation of the new solution and its significant advantages in reducing waveguide length, reducing signal attenuation, and reducing floor weight.

a Corresponding author: doriapompom123@163.com 


\section{Thermal test RF link scheme design}

\subsection{RF transmission in thermal test}

Most of the satellite transponder thermal tests use metal rectangular waveguides to design transmission links. This paper takes the design of some satellite thermal test waveguide as an example. Firstly, the water cooling load layout method and the thermal test waveguide path were designed. Secondly, a brief demonstration and analysis for the design of the internal structure and the wall current of the guided mode were carried out.

\subsection{Waveguide Path Design and Analysis in thermal test}

There were 32 microwave loads would be installed in a satellite thermal test and must be fixed on the satellite boards. If all the models used as the previous models (directly fixed on the floor), it will be difficult to connect the water cooling load layout. We proposed two plans to solve this problem.

a. According to the design of the repeater, the forward outputs could be divided into two groups, and then the signal power synthesized by the external output multiplexer and then connected the water-load. However, the newly-manufactured output multiplexers needed to be redesigned and debugged with a period of at least 3 months.

b. The problem of fixing the water-load was solved by increasing the adapter plate. This program required $6 \sim 8$ adapter plates, but the design time of the adapter plate and waveguide could be reduced within 1 month.

After considering the degree of difficulty and progress time, Option b was more feasible than Option a.

\subsection{The Theory of Internal Field Calculation of Metal Rectangular Waveguide}

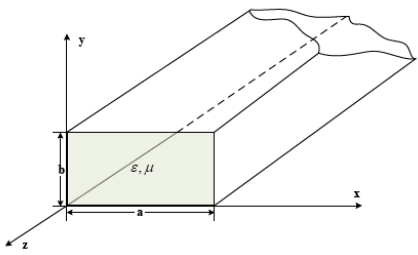

Figure 1. WR51 Waveguide $(\mathrm{a}=12.96 \mathrm{~mm}, \mathrm{~b}=6.48 \mathrm{~mm}$ )

As shown as figure 1, according to Maxwell Differential form of equation,

Boundary conditions,

$$
\left.\begin{array}{c}
\nabla \times \mathrm{E}=-\frac{\partial B}{\partial t} \\
\nabla \times \mathrm{H}=-\frac{\partial D}{\partial t}+J \\
\nabla \times \mathrm{B}=0 \\
\nabla \times \mathrm{D}=\rho \\
\mathrm{D}=\varepsilon \mathrm{E}=\varepsilon_{0} \varepsilon_{r} E \\
\mathrm{~B}=\mu \mathrm{H}=\mu_{0} \mu_{r} H \\
J=\sigma E
\end{array}\right\}
$$

$$
E_{x}=0, E_{n}=\frac{\sigma}{\varepsilon_{0}}, H_{t}=i, H_{n}=0
$$

According to (1), (2), the $\mathrm{TE}_{10}$ electric field component and magnetic component of no loss infinity WR51 waveguide could be solved, 


$$
\left.\begin{array}{c}
E_{x}=E_{z}=0 \\
E_{y}=E_{0} \sin \left[\frac{\pi x}{a}\right] e^{j(\omega t-\beta \mathrm{z})} \\
H_{x}=-\frac{\beta}{\omega \mu} E_{0} \sin \left[\frac{\pi x}{a}\right] e^{j(\omega t-\beta \mathrm{z})} \\
H_{y}=0 \\
H_{z}=-j \frac{\pi}{\omega a \mu} E_{0} \cos \left[\frac{\pi x}{a}\right] e^{j(\omega t-\beta \mathrm{z})}
\end{array}\right\}
$$

In formula(3), Phase constant $\beta=2 \pi / \lambda_{\mathrm{g}}$;

Waveguide wavelength $\lambda_{\mathrm{g}}=\lambda_{0} \sqrt{1-\left(\lambda_{0} / \lambda_{\mathrm{c}}\right)^{2}}$;

Critical wavelength $\lambda_{\mathrm{c}}=2 \mathrm{a}$;

Free space wavelength $\lambda_{0}=\mathrm{c} / \mathrm{f}$

In formula(3),WR51 only exist $E_{y}$ in mode $\mathrm{TE}_{10}$. In flat $\mathrm{xy}, \mathrm{E}_{\mathrm{y}}=\mathrm{E}_{0} \sin (\pi \mathrm{x} / \mathrm{a})$. The electric field intensity was only related to $\mathrm{x}$ axis and it changed as sine law. When $\mathrm{y}=0, \mathrm{x}=\mathrm{a}$, then $\mathrm{E}_{\mathrm{y}}=0$. When $\mathrm{x}=\mathrm{a} / 2, \mathrm{E}_{\mathrm{max}}$. When energy travels in the $\mathrm{z}$ direction, $\mathrm{E}_{\mathrm{y}}$ would be in traveling wave state in $\mathrm{z}$ direction. And in profile of $\mathrm{x}=\mathrm{a} / 2, \mathrm{E}_{\mathrm{y}}$ sine distribution in $\mathrm{z}$ direction. The magnetic field in WR51 had $\mathrm{H}_{\mathrm{x}}, \mathrm{H}_{\mathrm{z}}$ Component. Magnetic lines were distributed in the flat xz. Affinity relationship of $\mathrm{E}_{\mathrm{y}}$ and $\mathrm{H}_{\mathrm{x}}$ decided the energy travelled in $\mathrm{z}$ direction. When $\mathrm{E}_{\mathrm{y}}$ and $\mathrm{H}_{\mathrm{x}}$ in same direction, $\mathrm{E}_{\mathrm{y}}$ and $\mathrm{H}_{\mathrm{x}}$ reached maximum. When in $x$ direction, $E_{y}$ and $H_{x}$ in same direction, sine distribution, the same as in cross section and longitudinal section. In $\mathrm{z}=0$ section, $\mathrm{H}_{\mathrm{z}}$ cosine changed in $\mathrm{x}$ direction. And in position of $\mathrm{x}=0, \mathrm{x}=\mathrm{a}, \mathrm{H}_{\mathrm{z}}$ was maximum, in position of $\mathrm{x}=\mathrm{a} / 2, \mathrm{H}_{\mathrm{z}}=0$.

\subsection{Metal Rectangle Waveguide Wall Current Calculation Principle}

Wall current size and direction were determined by the tangential magnetic field near the wall,

$$
J_{\delta}=\hat{n} \times H_{\text {tan }}
$$

Rectangular waveguides almost working in the $\mathrm{TE}_{10}$ mode. According to(3)(4)

$(y=0)(y=b), \hat{n}= \pm y$,

$$
\begin{aligned}
& J_{\delta}=\hat{y} \times\left[\hat{x} H_{x}+\hat{z} H_{z}\right]=\hat{x} H_{x}-\hat{z} H_{z}=\left[H_{10} \cos \left(\frac{\pi x}{a}\right) \hat{x}-\mathrm{j} \frac{\beta a}{\pi} H_{10} \sin \left(\frac{\pi x}{a}\right) \hat{z}\right] e^{j(\omega t-\beta z)} \\
& J_{\delta}=\hat{y} \times\left[\hat{x} H_{x}+\hat{z} H_{z}\right]=-\hat{x} H_{x}+\hat{z} H_{z}=\left[-H_{10} \cos \left(\frac{\pi x}{a}\right) \hat{x}+\mathrm{j} \frac{\beta a}{\pi} H_{10} \sin \left(\frac{\pi x}{a}\right) \hat{z}\right] e^{j(\omega t-\beta z)} \\
& \hat{n}=\hat{x}
\end{aligned}
$$

$$
J_{\delta}=\hat{x} \times \hat{z} H_{Z}=-\hat{y} H_{Z}=H_{10} e^{j(\omega t-\beta \mathrm{z})} \hat{\mathrm{y}}
$$

$\hat{n}=-\hat{x}$

$$
J_{\delta}=-\hat{x} \times \hat{z} H_{Z}=\hat{y} H_{Z}=-H_{10} e^{j(\omega t-\beta z)} \hat{y}
$$

Therefore, when in mode $\mathrm{TE}_{10}$, the wall current only had $\mathrm{J}_{\mathrm{y}}$, in same size and direction. In the up and down wall, the current consist of $\mathrm{J}_{\mathrm{x}}$ and $\mathrm{J}_{\mathrm{z}}$. In the same position $-\mathrm{x}$, the wall current in same size but in opposite direction[3].

\section{Optimization and data comparison}




\subsection{Pre-optimization plan and test results}

This paper chosed $12 \mathrm{Rf}$ links among the $32 \mathrm{RF}$ links in some satellite. According to plan $\mathrm{b}$ in 2.2, the number of waveguide as following table 1 shows,

Table 1. Quantity statistics for Pre-optimization plan

\begin{tabular}{ccccc}
\hline Port No. & Straight & E Bend & H Bend & Twist or Soft \\
\hline 101 & 5 & 1 & 2 & 0 \\
102 & 6 & 2 & 2 & 1 \\
103 & 4 & 2 & 1 & 0 \\
104 & 5 & 1 & 1 & 0 \\
105 & 6 & 2 & 2 & 0 \\
106 & 4 & 1 & 1 & 1 \\
107 & 4 & 2 & 0 & 1 \\
108 & 3 & 2 & 1 & 0 \\
109 & 2 & 1 & 1 & 0 \\
110 & 4 & 2 & 1 & 1 \\
111 & 5 & 1 & 1 & 1 \\
112 & 3 & 2 & 1 & 0 \\
\hline
\end{tabular}

To verify that the waveguide assembly met the electrical performance requirements and that the waveguide assembly needed to be tested prior to testing. The test included VSWR and Insertion Loss. The data were shown in the table 2 .

Table 2. Component electrical performance test data

\begin{tabular}{ccccc}
\hline Port No. & $\begin{array}{c}\text { Insertion Loss } \\
\text { Index }(\mathrm{dB} / \mathrm{m})\end{array}$ & $\begin{array}{c}\text { VSWR } \\
\text { Index }\end{array}$ & $\begin{array}{c}\text { VSWR } \\
\text { DATA }\end{array}$ & $\begin{array}{c}\text { IL } \\
\text { DATA }(\mathrm{dB} / \mathrm{m})\end{array}$ \\
\hline 101 & 0.25 & $1.2: 1$ & 1.55 & 0.58 \\
102 & 0.25 & $1.2: 1$ & 1.69 & 0.59 \\
103 & 0.25 & $1.2: 1$ & 1.45 & 0.4 \\
104 & 0.25 & $1.2: 1$ & 1.53 & 0.32 \\
105 & 0.25 & $1.2: 1$ & 1.72 & 0.45 \\
106 & 0.25 & $1.2: 1$ & 1.68 & 0.58 \\
107 & 0.25 & $1.2: 1$ & 1.72 & 0.54 \\
108 & 0.25 & $1.2: 1$ & 1.39 & 0.54 \\
109 & 0.25 & $1.2: 1$ & 1.35 & 0.58 \\
110 & 0.25 & $1.2: 1$ & 1.92 & 0.61 \\
111 & 0.25 & $1.2: 1$ & 1.67 & 0.42 \\
112 & 0.25 & $1.2: 1$ & 1.38 & 0.51 \\
\hline
\end{tabular}

Although this program could meet the current thermal test requirements of transponders the design was not only too complicated, but also cost lots of time. The water-load would be fixed to the satellite's board, it can affect satellite's life. In order to simplify the tooling and shorten the test design cycle, a test scheme was put forward to mount the water-cooled load directly on the adjustable bracket. The solution could reduce the VSWR and insertion loss value of the waveguide assembly. And it also helped water-load completely depart from the satellites. The new method could effectively solve the interference problem between the transponder thermal test waveguide assembly and the on-board equipment. 


\subsection{Structural optimization and analysis}

The new scheme minimized the waveguide design path. Water-cooled load which was fixed on the adjustable bracket could have at least $10 \mathrm{~mm}$ adjustment margin in three dimensions. Reduced use of flexible or twisted waveguides, could greatly suppressed the attenuation of waveguide components [4]. After accounting and testing the new path, the number of waveguide components and electrical performance test results were shown in the table 3, and the VSWR data were shown in table 4.

Table 3. Optimized water-cooled load loop waveguide specification statistics

\begin{tabular}{ccccc}
\hline Port No. & Straight & E Bend & H Bend & Twist or Soft \\
\hline 101 & 1 & 1 & 1 & 0 \\
102 & 2 & 1 & 0 & 0 \\
103 & 2 & 0 & 1 & 0 \\
104 & 2 & 1 & 1 & 0 \\
105 & 2 & 0 & 1 & 0 \\
106 & 1 & 0 & 0 & 0 \\
107 & 1 & 1 & 0 & 0 \\
108 & 1 & 1 & 0 & 0 \\
109 & 2 & 1 & 0 & 0 \\
110 & 2 & 1 & 0 & 0 \\
111 & 1 & 1 & 0 & 0 \\
112 & 2 & 1 & 0 & 0 \\
\hline
\end{tabular}

Table 4. Optimized component electrical performance test data

\begin{tabular}{cccc}
\hline Port No. & Frequency $(\mathrm{GHz})$ & $\begin{array}{c}\text { VSWR } \\
\text { DATA }\end{array}$ & IL DATA(dB/m) \\
\hline 101 & $17-21$ & 1.16 & 0.16 \\
102 & $17-21$ & 1.08 & 0.31 \\
103 & $17-21$ & 1.14 & 0.35 \\
104 & $17-21$ & 1.14 & 0.37 \\
105 & $17-21$ & 1.06 & 0.40 \\
106 & $17-21$ & 1.07 & 0.31 \\
107 & $17-21$ & 1.11 & 0.33 \\
108 & $17-21$ & 1.18 & 0.21 \\
109 & $17-21$ & 1.10 & 0.66 \\
110 & $17-21$ & 1.03 & 0.33 \\
111 & $17-21$ & 1.15 & 0.32 \\
112 & $17-21$ & 1.04 & 0.29 \\
\hline
\end{tabular}

Compared with table 2, it was obviously to found, VSWR and insertion loss values were greatly reduced, and the program effectiveness could be verified.

\section{Actual design study}

Based on the research in the previous section, the water-cooled load distribution optimization design was performed for a certain type of satellite transponder thermal test waveguide assembly[5]. In order 
to fixed 32 water-loads on board, Satellites needed to be opened on the east and west boards for the adapter plate during thermal reform if we chose original plan. It was estimated that approximately 500 test waveguides were needed. In addition, it was also necessary to design a microwave-loaded circulating water pipeline with a long implementation cycle and high operational risk.

The adventure of optimization design had 4 aspects,

- Reducing the output of experimental waveguide designs.

- Main line work auxiliary line.

- Reduce design interface

- Reduce test preparation difficulty and implementation risk.

\section{Conclusions}

By analysing the current design of the power absorbing waveguide in the transponder sub-system tank, the factors influencing signal attenuation were described in detail. Based on the original scheme, an adjustable bracket scheme that installs the water cooling load away from the satellite panel was proposed and compared. After the signal standing wave and insertion loss in the original scheme and optimization scheme, the optimized scheme has great advantages in reducing the signal attenuation value, reducing the number of used waveguide components, reducing the use of twisted waveguides and flexible waveguides, and even not using them. At the same time, the optimized solution can reduce the weight of satellite panels and increase the service life of satellites by solving the problems of complicated waveguide design and complicated installation.

\section{References}

1. Gan Zhngmin, Zhang Gengxin. Current development of satellite communications technology[A], Journal on Communications,2006,27(8)

2. Yang Yong, Liu Bo, Wang Jue, Tian Ye. The thermal vacuum test for telecommunication satellite[A], Spacecraft Environment Engineering,2013, 30(3),275-279

3. Li Yuankai. The Research of Water Load Power Meter with Waveguide Structure[J].

4. Xue Renwei, Xue Yaoming, Yu Boying. High power flexible rectangular waveguide[J]. Option Fiber \& Electric Cable, 2005,(5):18-20

5. Li Te, Hao Erjuan, Li Zaijin,Wang Yong, Lu Peng, Qu Yi. Optimization of waveguide structure for high power 1060nm laser[J], Infrared Millim Waves, 2012,(3),226-230 